\title{
Effect of loading rate on the fracture behaviour of high-strength concrete
}

\author{
G. Ruiza ${ }^{\text {, X. X. Zhang }}{ }^{\text {, }}$ R. C. Yu, E. Poveda, R. Porras and J. del Viso \\ Universidad de Castilla-La Mancha, 13071 Ciudad Real, Spain \\ agonzalo.ruiz@uclm.es, ${ }^{b}$ zhangxiaoxinhrb@gmail.com
}

Keywords: loading rate, high-strength concrete, fracture energy.

\begin{abstract}
This research deals with the sensitivity of eight types of performance-designed highstrength concrete to the loading rate. Variations in the composition of the concrete produce the desired performance, for instance having null shrinkage or being able to be pumped at elevated heights without segregation, but they also produce variations in the fracture properties that are reported in this paper. We performed tests at five loading rates spanning six orders of magnitude in the displacement rate, from $1.74 \times 10^{-5} \mathrm{~mm} / \mathrm{s}$ to $17.4 \mathrm{~mm} / \mathrm{s}$. Load-displacement curves show that their peak is higher as the displacement rate increases, whereas the corresponding displacement is almost constant. Fracture energy also increases, but only for loading rates higher than $0.01 \mathrm{~mm} / \mathrm{s}$. We use a formula based on a cohesive law with a viscous term to study the results. The correlation of the formula to the experimental results is good and it allows us to obtain the theoretical value for the fracture energy under strictly static conditions. In addition, both the fracture energy and the characteristic length of the concretes used in the study diminish as the compressive strength of their aggregates increases.
\end{abstract}

\section{Introduction}

Compared with the extensive research into the static fracture behaviour of high-strength concrete, much less information is available on its dynamic fracture behaviour [1-4]. Schuler and Hansson [1] measured the tensile strength and the fracture energy of high-strength concretes at high strain rates between $10 \mathrm{~s}^{-1}$ and $100 \mathrm{~s}^{-1}$ with spalling tests. A three-fold increase in the fracture energy was observed at a crack opening velocity of $1.7 \mathrm{~m} / \mathrm{s}$. Nevertheless, the experimental data in scientific literature on the rate-sensitivity of the fracture behaviour of high-strength concrete is scarce.

In the case of conventional concrete however, there is abundant information on the subject. The fracture energy varies slightly under quasi-static loading if there is a variation in the loading rate, while the fracture energy changes under dynamic loading [5]. Thus some researchers deduce that the fracture energy is constant and independent of the loading rate [6-8]. However, the fracture energy increases by approximately 50\% when the loading rate increases until about $1 \mathrm{~mm} / \mathrm{s}$ [9]. Under high loading rates, the fracture energy greatly exceeds the static value, mainly due to structural causes, such as inertia and the geometry of the structure [10-12].

In addition, results and conclusions obtained with conventional concretes are not directly applicable to high-strength concrete, as the type and extent of the fracture process zone varies with the increasing strength of the material. In general, cracks tend to propagate around aggregates in conventional concrete, whereas in high-strength concrete, they usually go through them $[13,14]$. According to Carpinteri and Paggi [15], the super-singular behaviour of transgranular cracks may be a possible reason of the less pronounced effect of crack arrest by aggregates and a more brittle global behaviour of high-strength concrete. This fact implies that we should review the formulations obtained in the study of the fracture of conventional concrete when it will be used in high-strength concrete.

Therefore, in this research we want to study the variation of fracture energy in eight types of high-strength concretes designed for performance. By this we mean that besides being of high strength the concrete is required to have a special feature. Both requirements determine the mixture 


\begin{tabular}{|c|c|c|c|c|c|c|c|}
\hline features & nomenclature & $\begin{array}{c}\text { Coarse } \\
\text { aggregate }\end{array}$ & $\begin{array}{c}d_{\text {máx }} \\
(\mathrm{mm})\end{array}$ & $\begin{array}{c}f_{c} \text { aggregate } \\
(\mathrm{MPa})\end{array}$ & $\begin{array}{c}E_{c} \\
(\mathrm{GPa})\end{array}$ & $\begin{array}{c}f_{c} \\
(\mathrm{MPa})\end{array}$ & $\begin{array}{c}f_{t} \\
(\mathrm{MPa})\end{array}$ \\
\hline Conventional plant & H01 & silicious & 20 & 130 & $32(2)$ & $78(4)$ & $6.3(0.4)$ \\
\hline Pumpable & $\mathrm{HO} 2$ & andesite & 12 & 250 & $30(2)$ & $88(4)$ & $5.8(0.7)$ \\
\hline Without retraction & H03 & andesite & 12 & 250 & $34(1)$ & $97(6)$ & $6.1(0.5)$ \\
\hline Very high strength & H05 & porphyry & 12 & 200 & $43(2)$ & $127(11)$ & $6.3(0.6)$ \\
\hline High early strength & H06 & mylonite & 6 & 150 & $34(1)$ & $71(11)$ & $4.9(0.3)$ \\
\hline Low heat of hydration & H07 & andesite & 12 & 250 & $29(4)$ & $96(14)$ & $5.3(0.7)$ \\
\hline Light & H08 & arlite & 10 & 10 & $20(1)$ & $57(5)$ & $3.0(0.4)$ \\
\hline Heavy & H09 & barite & 10 & 12 & $34(1)$ & $60(1)$ & $3.7(0.4)$ \\
\hline
\end{tabular}

Table 1. Performance of design, type of aggregate used and mechanical properties of high strength concretes.

components of the concrete and its strength. The variations in the composition of the concrete, while providing the desired benefit, also produce changes in mechanical properties in fracture and, therefore, another objective of this study is to ascertain the relationship between the composition of high-strength concrete and its properties in fracture. The process of design, fabrication and the curing state of the material (for example, properties in fresh state, especially the thixotrophic changes characteristic of the use of additives) is complementary to this research and, of course, is of great technological interest. However, they are located outside of the limits of the fracture mechanical characterization of materials and therefore we have excluded this part in our work. We will only consider, as a complement to our primary objective, the influence of the composition of the concrete on the mechanical properties in fracture.

\section{Experimental Program}

High-strength concrete. The concretes studied in this investigation were designed and manufactured by Composites ID in its factory in Alpedrete (Madrid). The provision of design and nomenclature adopted for each of them are shown in Table 1 (in the nomenclature there is a gap from $\mathrm{H} 03$ to $\mathrm{H} 05$, this is because $\mathrm{H} 04$ was planned but not made in the end, nevertheless we respected the initial name of the concrete that Composites ID had agreed to). From a mechanical point of view its composition can be characterized by the type of coarse aggregate used, by its maximum size and compressive strength [16], this information is also included in Table 1. In addition this table provides the results of standard mechanical characterization tests (elastic modulus, Ec, compressive strength, $\mathrm{fc}$, and indirect tensile strength, $\mathrm{ft}$, besides the average value of these four tests, in brackets, it shows the standard deviation). For the compressive tests, we used 75 x $150 \mathrm{~mm}$ cylinders (diameters x height) and followed the recommendations of ASTM C39. The elastic modulus was measured using two clip strain gages centered in opposite generatices.

Tests for fracture energy. In this work we measured the fracture energy, $\mathrm{G}_{\mathrm{F}}$, through three-point bending tests with the procedure recommended by RILEM [17] and with the improvements proposed by Planas, Guinea and Elices [18]. In particular, the dimensions of the specimen are $100 \times 100 \times 400 \mathrm{~mm}$, the initial notch-depth ratio is approximately 0.5 . The tests were conducted in position control at five loading rates: $17.4 \mathrm{~mm} / \mathrm{s}$ (very fast), $0.55 \mathrm{~mm} / \mathrm{s}$ (fast), $1.74 \times 10^{-2} \mathrm{~mm} / \mathrm{s}$ (intermediate), $5.5 \times 10^{-4} \mathrm{~mm} / \mathrm{s}$ (slow) and $1.74 \times 10^{-5} \mathrm{~mm} / \mathrm{s}$ (very slow). In the case of slow and very slow tests loading rates displayed were the first $0.25 \mathrm{~mm}$ of loading-point displacement.

This displacement always includes peak load in the first ramp. Then the test is accelerated by multiplying the rate by five to $0.75 \mathrm{~mm}$ of loading point displacement, and then, multiplying by five again until the end of the test. The slowest tests last about 8 hours while the fastest tests last approximately $1 / 5$ th of a second.

\section{Results}

Figure 1 shows the typical load-displacement curves $(P-\delta)$ of the concrete $\mathrm{H} 03$ at each loading rate. Each curve produces a value of $G_{F}$. The average values of $G_{F}$ and the loading rate for each concrete 


\begin{tabular}{cccccc}
\multicolumn{5}{c}{$G_{F}[\mathrm{~N} / \mathrm{m}]$ to loading rate $v_{D}[\mathrm{~mm} / \mathrm{s}]$} \\
$v_{D}$ & $1.74 \times 10^{-5}$ & $5.5 \times 10^{-4}$ & $1.74 \times 10^{-2}$ & 0.55 & 17.4 \\
\hline H01 & $211(13)$ & $200(41)$ & $197(26)$ & $249(35)$ & - \\
H02 & $121(28)$ & $108(13)$ & $119(11)$ & $156(16)$ & $177(9)$ \\
H03 & $134(14)$ & $126(6)$ & $124(8)$ & $155(12)$ & $198(23)$ \\
H05 & $181(43)$ & $156(20)$ & $187(12)$ & $215(18)$ & $252(39)$ \\
H06 & $245(22)$ & $213(9)$ & $254(42)$ & $285(24)$ & $328(62)$ \\
H07 & $149(16)$ & $137(11)$ & $157(3)$ & $158(7)$ & $204(25)$ \\
H08 & $120(3)$ & $100(8)$ & $97(5)$ & $113(12)$ & $111(2)$ \\
H09 & $153(11)$ & $138(13)$ & $139(25)$ & $169(40)$ & $201(19)$
\end{tabular}

Table 2: Variation of fracture energy with loading rates

are provided in Table 2 (in the case of H01-mixed

in a pre-cast plant- $G_{F}$ was not measured for the very fast loading rate). The standard deviation of each measurement is shown between brackets.

\section{Discussion}

Variation of the mechanical properties depending on aggregate type. Figure 2 represents the relation between the concrete's mechanical properties and the compressive strength of coarse aggregates. It is clear that the compressive strength of the concretes increases almost in a linear way (except H05) with an increase in the compressive strength of aggregates. As concerns the tensile strength of the concretes, the increase is significant at first and slight later with increases in the compressive strength of aggregates. For the concrete H05 (very high strength), the increase is more pronounced for both properties. It could be that it was produced with a high quantity of additives (microsilica) [19].
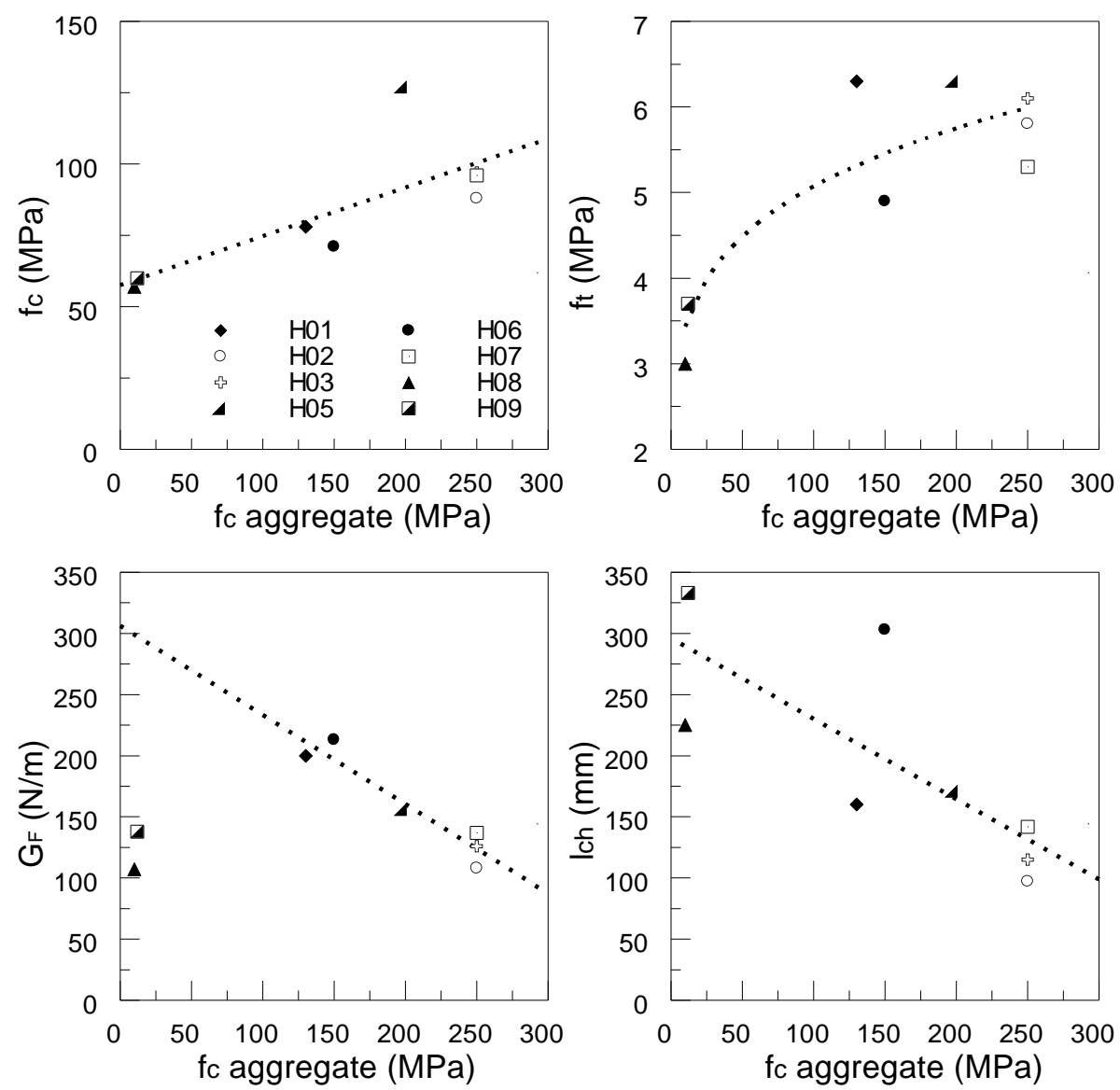

Fig. 2: Variation of the mechanical properties in relation to the compressive strength of coarse aggregates. 
With regard to the variation of the elastic modulus with aggregates strength, Table 1 shows that the modulus is kept in an interval between 30 and $35 \mathrm{MPa}$ approximately, except for the H08 concrete (light) and the H05 concrete (very high strength). The H08 concrete (light) is composed of an artificial aggregate, arlite, this is an expanded clay and has an elastic modulus far lower than the rest of the aggregates. The increase in the elastic modulus of the H05 concrete (very high strength) is attributable partially to the porphyry aggregate that is used in its composition and partially to the fact that the matrix is more rigid and resistant [19].

Regarding the variation of the specific fracture energy $G_{F}$ with aggregate strength, Figure 2 clearly shows that $G_{F}$ decreases with an increase in the compressive strength of the aggregate, except in the case of concretes with aggregates of a weaker strength (H08 and H09). Fig. 2 also shows that the characteristic length, $\ell_{c h}$, decreases with increases in coarse-aggregate strength. It confirms, from a fracture mechanics view point, that the strongest concretes are the most fragile. It is important to remember that the length of fracture process and the release of fracture energy in concrete are proportional to $\ell_{c h}$. Therefore, two similar structures that have the same proportion of their dimensions with $\ell_{c h}$ are going to generate similar crack processes with proportional dimensions and, in this respect, $\ell_{c h}$ characterizes the ductility or intrinsic brittleness of concrete.

Variation of fracture energy with loading rate. Figure 1 shows typical load-displacement curves, $P-\delta$ under different loading rates for the concrete $\mathrm{H} 03$ (without retraction). The peak load increases with an increase in the loading rate, whereas the displacement in maximum load remains practically constant. Regarding the stiffness of the beam, it is observed that, as with the peak load, it also increases with increases in the loading rate.

In Table 2 we arrange the values of $G_{F}$ obtained from fracture energy tests for all of the concretes at the five loading rates next to their corresponding standard deviation in brackets, in contrast Fig. 4 represents average values graphically. It is observed that the fracture energy remains practically constant for quasi-static loading rates but increases in value for dynamic loading rates. For all of the concretes, note that the value of $G_{F}$ at the lowest loading rate is slightly greater than that obtained for the following two loading rates (slow and intermediate loading rates). A possible explanation for this recovery of $G_{F}$ can be in the humidity loss of the specimen during the slowest test, since the duration of the fracture process was approximately eight hours. On the other hand, the increase of $G_{F}$ with increases in loading rate is attributable to a major extension of the microcraking zone around the principal fracture [20-22].

It is clear that, for static and quasi-static loading rates, from $1.74 \times 10^{-5} \mathrm{~mm} / \mathrm{s}$ up to $1.8 \times 10^{-2} \mathrm{~mm} / \mathrm{s}$, the fracture energy scarcely changes -though the maximum load changes (See Fig. 1)-, which would explain why some researchers should have thought that fracture energy is independent from loading rate [6-8]. For higher loading rates $G_{F}$ increases sensitively (with the exception of $\mathrm{H} 08$-light-, probably due to the different nature of its coarse aggregate). We think that the movement of water through the network of pores of material, and the formation of a new surface of water in the way of spread of the fissures, have an influence on the variation of the peak load and the fracture energy with the loading rate that is shown in the experimental results. The aforementioned variation reproduces correctly using a cohesive model which includes a term dependent on the loading rate [23]. This approximation allows us to deduce that the adjustment to the experimental results would be of the type:

$$
\frac{G_{F}}{G_{F}^{S}}=1+\left(\frac{v_{D}}{v_{0}}\right)^{n} .
$$

Where $G_{F}$ is the fracture energy, $G_{F}^{s}$ is a parameter of adjustment with dimensions of fracture energy, $v_{D}$ is the loading rate, $v_{0}$ is another parameter of adjustment, with rate dimensions, 

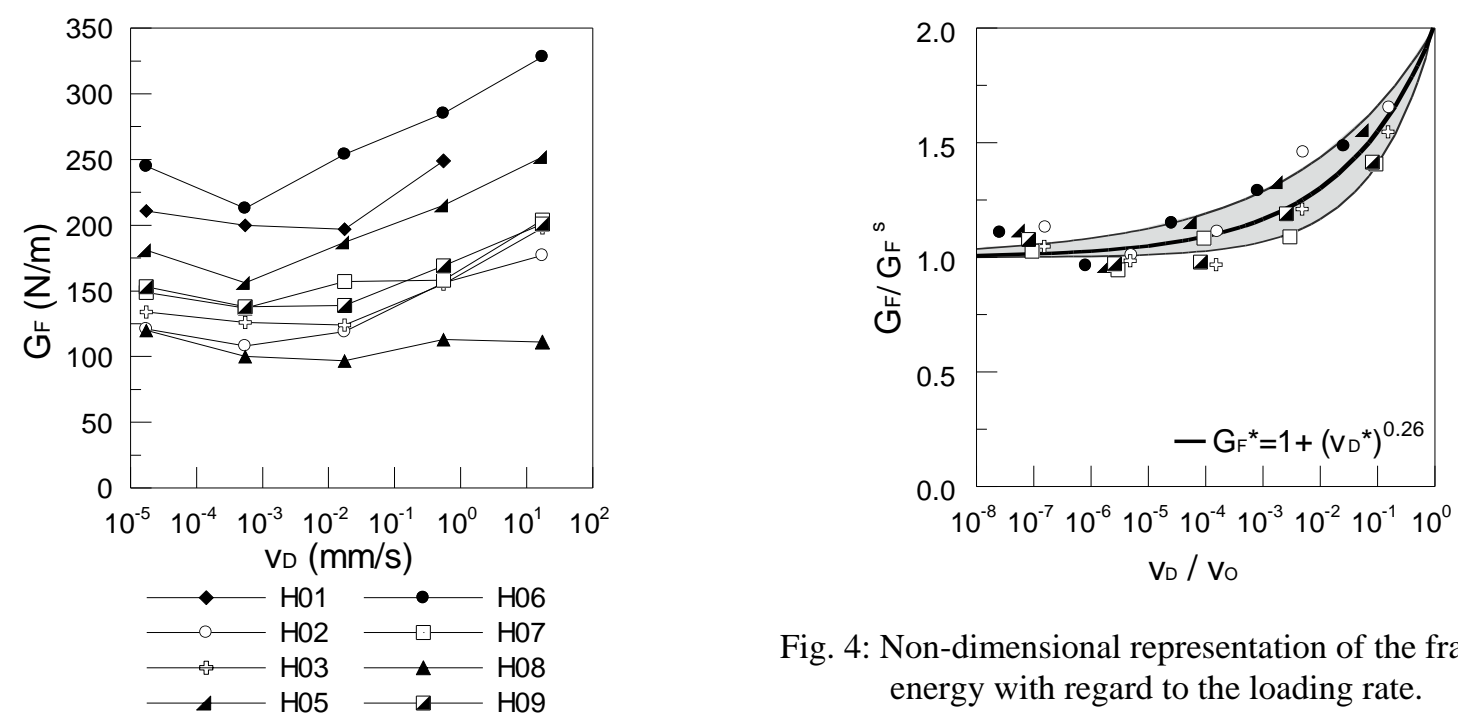

Fig. 4: Non-dimensional representation of the fracture energy with regard to the loading rate.

Fig. 3: Variation of fracture energy with loading rate.

and $n$ is a non-dimensional exponent which describe the degree of viscosity of the material, obtained from fitting Eq. 1 to the experimental results.

In Table 3 we present the parameters that fit Eq. 1 to each type of concrete. The regression coefficients turn out to be almost 1 except in the case of H01 (mixed in a pre-cast plant), due to the fact that $G_{F}$ did not measure for the very fast rate, and also in the case of H08 (light), due to its anomalous behavior; for this reason, the parameters corresponding to these two concretes are not displayed in Table 3.

It is necessary to emphasize that $G_{F}^{s}$ can be understood as the value of the fracture energy for strictly static conditions $\left(v_{D}=0\right)$. It can be observed that the aforementioned parameter practically coincides, in all cases, with the fracture energy measured at slow velocity, which is habitually considered to be an intrinsic material property. On the other hand, $v_{0}$ is a parameter that represents the displacement rate that would produce a 100\% increase in the fracture energy, compared with the static value; it is a parameter whose value may be between $10^{2}$ and $10^{3} \mathrm{~mm} / \mathrm{s}$ and its average is $284 \mathrm{~mm} / \mathrm{s}$. The exponent $n$ changes from between 0.2 and 0.4 , and its average value is 0.27 .

\begin{tabular}{cccc} 
& $G_{F}^{s}[\mathrm{~N} / \mathrm{m}]$ & $v_{0}[\mathrm{~mm} / \mathrm{s}]$ & $n$ \\
\hline H01 & - & - & - \\
H02 & 106 & 125 & 0.18 \\
H03 & 126 & 91 & 0.33 \\
H05 & 162 & 317 & 0.20 \\
H06 & 221 & 733 & 0.19 \\
H07 & 145 & 180 & 0.39 \\
H08 & - & - & - \\
H09 & 142 & 256 & 0.32
\end{tabular}

Table 3: Parameters of the equation of adjustment for each concrete.

Figure 4 represents the experimental results of non-dimensional way. The $x$-axis corresponds to the non-dimensional velocity $v_{D} / v_{0}$ and the $\mathrm{y}$-axis corresponds to the nondimensional fracture energy with regard to $G_{F}^{S}$. In this figure, each concrete has been represented using its corresponding parameters indicated in Table 3. Two fitting curves bridged by the shaded zone are intended to cover most of the experimental data points. A new fit (the thick line) Eq. 1 to pass the center of the shaded zone gives an $n$ of 0.26 , which is very closet to the value average found above (0.27). This fit represents the non-dimensional average behaviour of the high-strength concretes in this study. 


\section{Summary and Conclusions}

In this research we have investigated the loading-rate sensitivity of the fracture energy of eight high-strength concretes designed for benefits, such as being pumped or without retraction. With each type of concrete we performed tests to measure fracture energy at five different loading rates, from $1.74 \times 10^{-5} \mathrm{~mm} / \mathrm{s}$ to $17.4 \mathrm{~mm} / \mathrm{s}$. Load-displacement curves show that the maximum load increases with an increase in loading rates, yet the corresponding displacement remains almost constant. The fracture energy value increases with the loading rate from $0.01 \mathrm{~mm} / \mathrm{s}$. The results fit perfectly with a formula based on a cohesive model with a viscous term. With this adjustment we have obtained the theoretical value of fracture energy in strictly static loading conditions.

We have also investigated the changes that the variations in the composition of the concretes produced in the fracture properties.

\section{References}

[1] H. Schuler and H. Hansson: Journal de Physique IV, Vol. 134 (2006), pps. 1145-1151.

[2] S. Mindess, N. Banthia, and C. Yan: Cement and Concrete Research, Vol. 17 (1987), pps. 231-241.

[3] H. Müller: CEB FIP Bulletin Vol. 42 (2008).

[4] X. Zhang, G. Ruiz, R. C. Yu, and M. Tarifa: International Journal of Impact Engineering, Vol. 16 (2009), pps. 1204-1209.

[5] B. Oh: Engineering Fracture Mechanics, Vol. 35 (1990), pps. 327-332.

[6] N. Challamel, C. Lanos, and C. Casandjian: International Journal of Damage Mechanics, Vol. 14 (2005), pps. 5-24.

[7] D. C. Jansen, S. P. Shah, and E. C. Rossow: ACI Materials Journal, Vol. 92 (1995), pps. 419428.

[8] J.H. Yon, N. M. Hawkins, and A. S. Kobayashi: ACI Materials Journal, Vol. 89(1992), pps. $146-153$.

[9] RILEM: Materials and Structures, Vol. 23 (1990), pps. 461-465.

[10] Y. Lu and K. Xu: International Journal of Solids and Structures, Vol. 41 (2004), pps. 131143.

[11] F. Toutlemonde. PhD Thesis, E.N.P.C., Paris (1994).

[12] J. Van Doormaal, J. Weerheijm, and L. Sluys: Journal de Physique IV, Vol. 4 (1994), pps. 501- 506.

[13] S. Choi, K. Thienel, and S. Sha: Magazine of Concrete Research, Vol. 48 (1996), pps. 103115.

[14] S. Caliskan, B. L. Karihaloo, and B. I. G. Barr: Magazine of Concrete Research, Vol. 54 (2002), pps. 449-461.

[15] A. Carpinteri and M. Paggi: Engineering Fracture Mechanics, Vol. 74 (2007), pps. 59-74.

[16] M. Alexander and S. Mindess, in: Aggregates in Concrete. Taylor \& Francis, Madison Ave, New York (USA), (2005).

[17] RILEM: Materials and Structures, Vol. 18 (1985), pps. 285-290. 
[18] M. Elices, G. V. Guinea, and J. Planas: Materials and Structures, Vol. 30 (1997), pps. 375376.

[19] J. Del Viso. Tesis doctoral, Universidad de Castilla-La Mancha, Ciudad Real (2008).

[20] Bischoff, P. H., and S. H. Perry: Materials and Structures, Vol. 24 (1991), pps. 425-450.

[21] Ahmed Brara and Janusz R. Klepaczko: International Journal of Impact Engineering, Vol. 34 (2007), pps. 424-435.

[22] I. Vegt, K. Van Breugel, and J. Weerheijm: Failure mechanisms of concrete under impact loading. Fracture Mechanics of Concrete and Concrete Structures, Vol. 1-3 (2007).

[23] G. Ruiz, X. Zhang, J. Del Viso, R. Yu, and J. Carmona, in: Anales de Mecánica de la Fractura, Vol. 25 (2008), pps. 793-798. 